\title{
Unbending Bakhtin's Carnivalisation and the Related Approaches in Othello
}

\author{
Nasser Maleki \\ Department of Foreign Languages and Literature, \\ Razi University, Kermanshah, Iran \\ Email:n.maleki@razi.ac.ir \\ Ali Poordaryaei Nejad \\ Assistant Professor of Hormozgan University \\ Bandar Abass, Iran \\ Maryam Navidi \\ PhD Student, University of Tehran, Iran
}

\section{Doi:10.5901/mjss.2013.v4n3p433}

\begin{abstract}
In the present article, the researchers have demonstrated a textual analysis of Shakespeare's Othello using Bakhtin's concept of Carnivalisation and its related approaches as tools of analysis. Passage of the time has approved that Shakespeare's tragedies still live out of time and place, because they are the repository of humanity. Therefore, his works can aptly be interpreted to gain new meanings in various societies with different cultures, and this can ultimately produce the polyphonic clash of struggles in his works. Consequently as these struggles become the subjects of the same society they resist against the dominant culture, or the dominant hierarchies, then it produces the second culture which is called carnival in the Bakhtinian canon. Considering such a hypothesis in mind, this study is to find the traces of Bakhtin's famous term carnivalisation and the related approaches in Shakespeare's Othello, the findings show that Shakespeare's Othello offers some hidden and dynamic repository of Bakhtin's views of poliphonism and carnival, it also foregrounds the idea of power-craving in a handy-dandy world
\end{abstract}

Keywords: Bakhtin; carnival; Shakespeare; Othello; power.

\section{Introduction}

The present article is divided into two parts: it first begins with a very brief introduction to Bakhtin's concept of Carnival as a sociological perspective in analyzing literary texts, which is then followed by utilizing the term in achieving new implications in one of the most frequented Shakespearian tragedies among literature students in Iranian universities called Othello whose author seems to have had very little in mind about Carnivalisation when he wrote it. This does not seem to have received enough attention by the researchers. A survey of the literature related to Shakespeare's Othello shows that it has been mainly approached through frameworks of formalism, exponential, determinism, feminism, psychoanalysis, etc. Hence, the researchers start analyzing a close study of the text of the play to foreground the possible traces of Bakhtin's famous term Carnival and its related approach. The article ends, conclusively, by briefly monitoring on the above concept as a philosophical doctrine that views reality in a Bakhtinian way, giving readers a chance to learn how to "ultimately develop their creative and critical faculties and ... create enough confidence in them to become autonomous" (Mishra 57) readers and critics of literature and literary texts, and the extracts cited in the main body of the article serve mainly to contextualize and support such a manifestation.

\section{Discussion}

We are here to introduce the veins of Carnival in Shakespeare's famous tragedy Othello. As it was known, comments Selden, "Shakespeare's tragedies have often been regarded as near-sacred texts which embody a profound understanding of human condition"(164). They have been valued as having universally and even time-less applications, therefore they can transparently be subjected to the new and modern strategies of reading and approaches like some of 
Bakhtin's views which, as we claim, are objectively enrooted in Othello written in sixteenth century Renaissance. It shows the genius of Shakespeare which is out of time and place; hence it can be assumed that Othello also has a diachronic (unhistorical) nature. Therefore, it can be presumed that every word of a literary work like Othello is capable to take the different meanings and connotatively historical situations, and can further become the clash of different voices, (which is called carnival); in order to gain the uni-accentual, social voice which is not possible, unless counter-identification or disidentification occurs, and it is a respond to the dominant voice. For Medvedev Bakhtin "rejected the whole notion of the isolated, finished, monologue utterance, divorced from its verbal and actual context and standing open not to any understanding" $(1978,43)$. In such condition, every voice in a literary art tries to collide and reverse the other voice and it is how the nature of a polyphonic novel or drama comes to the fore and these voices are set free to speak subversively or even shockingly, but without the author stepping between them. This phenomenon has a formative influence in the Renaissance and especially Shakespeare's Othello whose sense of joyful relativity or carnivalistic atmosphere, as Bressler depicts, "are heard and directly influenced their hearers"( 46). In the same vein, Bristol uses Bakhtin's concept of Carnival in order to introduce a more open model of cultural production, he says:

Bakthin regards carnival as a second culture which was opposed to the official culture, and which was carried on by the common people throughout the middle ages and well into the early, modern period. Bakhtin's idea that carnival inserts in to official structures an indeterminacy, a certain semantic opend-endedness could well provide, one way of describing how subjects might respond to dominant discourses through the modalities of counter-identification or even disidentification $(1985,36)$.

He summarizes the potentially subversive mode of carnival as he further says:

By bringing privileged symbols and officially authorized concepts into a crudely familiar relationship with common everyday experience, carnival achieves a transformation downward or uncrowning of dejure relations of dependency, expropriation and social discipline. Of course some Foucauldians would reply that carnival is also an officially permitted and carefully controlled expression of subversion which by its ritualized form only confirms the power of authority it mocks (Ibid: 41).

Carnivalisation is most of the time comic and vulgar, however one can transparently see it in a tragedy like Othello. In this tragedy, the main protagonist, Othello fits the center of conflicts; he is a moor, and this evokes the spirit of distinction which reveals that he is gradually deflected by other characters from the very beginning of the play. This fact is embodied in the conversation between lago and Roderigo. Here lago says:

Why, there's no remedy. Tis the course of service, preferment goes by letter and affection, And not by old gradation, where each second stood heir to the first. Now, sir, be judge yourself whether I in any just term an affined to love the $\operatorname{Moor}($ Act I, sce I).

Wherever the word 'Moor' is used in this play, it begins with capital letter and is followed by article 'the' to exemplify the distinction between Othello and other characters. Lexicographically speaking, the word 'Moor' means a member of a race of Muslim people living in NW Africa who entered and took control of part of Spain in the 8th century. Even in dictionary, it is capitalized too. In addition, all the characters of play call Othello differently, 'the Moor', 'black moor', 'sooty bosom' or even 'thick-lips owe' etc, other than his own name. This shows a sense of exotic distinction which further justifies that nobody admits him as his/her kinsman and this carnivalistic aspect of Othello continues until the end of play, and which Othello himself would like to reverse. Othello himself knows this condition as well, he says:

Let him do his spite.

My services which I have done the signiory shall out tongue his complaints. Tis yet to know- which, when I know that boasting is an honor, I shall promulgate-I fetch my life and being From men of royal siege, and my demerits may speak unbonneted to as proud a fortune As this that I have reached. For know, lago, but that I love the gentle Desdemona, I would not my unhoused free condition put into circumscription and confine for the sea's worth (Act I, sce I).

An essential feature of Carnival is the reversal of all hierarchies and conventional attitudes - hierarchies are turned on their heads - war changes to peace, loyalty changes to disloyalty, exotic becomes kinsman and love changes to hate. In the same token, Othello struggles to change his fixed position and acclaim new hierarchies, so he may be of 'royal siege', even "his unhoused free condition put into circumscription and confine for the sea's worth". Put differently, it is conceived that Othello accepts to be colonized in order to change his fixed position in the royal Greek society, and not to be 'unhoused' though he knows that this country won't easily let him dwell. Furthermore, what lago says in the next lines approves this fact that Othello is cultivated to be colonized, lago says: 
The Moor is of free and open nature that thinks men honest that but seem be so. And will as tenderly be led by the nose. As asses are (Act I, scn III).

As it is seen, there is a continuous flow of class struggle, and verbal signs in the background of the scene. Such verbal signs are also expressed in the moor's differentiated utterance. It seems even Shakespeare tries to set Othello apart by the vocabulary he puts into his mouth. This furthermore shows Othello's feelings of social unrest as the ruling class of Venice tries to narrow and marginalize him. In this sense, Bakhtin believes "in times of social unrest the rituality and basic multi-accentuality linguistic signs become apparent as various class interests clash and intersect upon the ground of language" $(1981,26)$. Hence, it is articulated that, the social unrest causes to bring into the surface the second culture which is the same as carnivalization, because Othello opposes the official culture, and his social unrest responds to the dominant discourses of Venice which is expressed through the modalities of counter-identification or misidentification. In the other part of the tragedy, Roderigo marking Othello as 'the thick-lips' says: What a full fortune does the thick-lip owe If he can carry't thus!(Ibid).

As it was said before, the Moor is races of Muslim people living in NW Africa, hence it is conceived that, the phrase, 'thick-lips' designates both cultural and racial difference in the discourse of colonialism which is stamped in Othello's face, and at the same time it is a kind of carnivalistic disrespect which Othello struggles to reverse. Put differently, it is a source of Foucault's idea of otherness which is an object of desire and derision, an articulation of difference contained within the fantasy of origin and identity. Such sense is transparently revealed in lago's conversation with Brabantio, he says:

Because we come to do you service and you think we are ruffians, you'll have your daughter covered with a Barbary horse, you'll have your nephews neigh to you, you'll have coursers for cousins, and jennets for germans (Act I, sce I).

Here, lago's expressions 'Barbary horse', and 'jennets' demand an articulation of forms of racial difference. These statements deny an original identity or a singularity to objects of racial difference, by which Shakespeare denigrates Othello, as both Barbar and the Moorish pony. The same interpretation comes to the fore when Roderigo, speaking sarcastically with Brabantio, calls Othello 'a lascivious Moor' and continues saying:

Your daughter (if you have not given her leave, I say again), hath made a gross revolt, Trying her duty, beauty, wit, and fortunes. In an extravagant and wheeling stranger of here and everywhere (Ac I, sce I).

In the above quotation the expression 'extravagant and wheeling stranger' which sarcastically refers to a wandering person refers to both lack of originality and fixity. Fixity is the sign of cultural, historical, and racial difference in the discourse of colonialism; it connotes rigidity and unchanging order as well as disorder, degeneracy and daemonic repetition. For it is the force of ambivalence that gives the colonial stereotype its currency; ensures its repeatability in changing historical and discursive conjunctures; informs its strategies of individuation and marginalization; produces that effect of probabilistic truth and predictability. This lack of originality continues to their next conversation, when lago meets Othello and says: Brabantio will divorce Othello. These references to the words spoken by these characters allude to the other term introduced by Bakhtin, called Heteroglossia, as he says:

\begin{abstract}
Heteroglossia is a fundamental concept referring to the basic condition governing the production of meaning in all discourse. It assets the way in which context defines the meaning of utterances, which are heteroglot in so far as they put in play a multiplicity of social voices and their individual expressions. A single voice may give the impression of unity and closure, but the utterance is constantly producing a plenitude of meanings, which stem from social interaction or dialogue $(1981,62)$
\end{abstract}

Bakhtin's views prove that, the consciousness of the various characters in Othello does not match with that of the author. They do not become subordinated to Shakespeare's viewpoint; instead they gain their new independence. In the final sections of Act I sc II, when Othello was summoned by the authorities, Branbantio being present there says:

I therefore apprehend and do attach thee. For an abuser of the world, a practiser of arts inhibited and out of warrant (Act I, sc II).

These lines contain a verbal irony; in fact Othello is abused by the world, though he is summoned 'for an abuser of the world'. Here one needs the knowledge of the colonizer and colonized which should be evaluated. The objective of the colonial discourse is to construe the colonized as a population of degenerate type on the basis of racial origin, in order to 
justify a conquest and to establish systems of administration and instruction. It, we assume, alludes to the fact that Othello is going to save his independence against them (the colonizers), and in turn it causes him to create a reversal of roles against the fixed position in the social hierarchy. The subsequent conversation of lago contains the fact that his discourse is involved in fixed power. He says:

\begin{abstract}
Virtue! A fig! Tis in ourselves that we are thus or thus. Our bodies are gardens, to the which our wills are gardeners. So that if we will plant nettles or sow lettuce, set hyssop and weed up thyme, supply it with one gender of herbs or district it with many, either to have it sterile with idleness or manured. With industry-why, the power and corrigible authority of this lies in our wills (Act I, sc III).
\end{abstract}

These lines contain the point which the German philosopher Nietzsche is concerned with, that is, "people first decide what they want and then fit the facts to their aim: Ultimately, man finds that all knowledge is an expression of the "will to fixed power" (42). This means that we can not speak of absolute truths or of objective knowledge. People recognize a particular piece of philosophy or scientific theory as true only if it fits the descriptions of truth lay down by the intellectual or political authorities of the day or by the members of ruling elite, or by the prevailing ideologues of knowledge. This also concerns Bakhtin's idea that, the production of meaning in all discourses referring to the context which defines the meaning of utterances, put in play a multiplicity of social voices and those which are subverted, and all these confirm the power of the authority.

In the other part of the play, as Emilia strides, the dominated authority wears the gown of a male-dominated society. Extrapolating on Bakhtin's argument that, what is true depends on who controls the dominant discourse, it is apparent that men's domination of discourse has trapped women inside a male truth. Hence, woman is riveted into a lopsided relationship with man, and in consequence man becomes the one, and woman the other, and the man's dominance secures an ideological climate of compliance. This male dominance and hierarchy is transparently shown in the play when lago, addressing Desdemona, says:

She that was ever fair and never proud, Had tongue at will and yet was never loud, Never lacked gold and yet went never gay, Fled from her wish and yet said "Now I may". She that, being angered, her revenge being night, Bade her wrong stay and her displeasure fly. She that in wisdom never was so frail To change the cod's head for the salmon's tail (Act II, sc I).

The essence of lago's remarks on Desdemona can be traced in one of Woolf's essays, 'Profession for Women' in which she regards her own career as hindered in two ways: the ideology of womanhood, the ideal of the Angel in the House called on women to be sympathetic, unselfish, and pure, and the taboo about expressing female passion prevented her from telling truth about her own experiences as a body' (84). It is completely visible that lago implicitly refers to a woman as 'the Angel in the House', like Desdemona, though his wife may not, so this sense frustrates their marriage, and makes Emilia unfaithful, and its testimony is approved in Emilia's dexterous affair with Cassio, hence her action is another instance of the carnivalistic disrespect and objection. However, lago's fixed position is sarcastically approved in his disapproval of Emilia, as he says: "You rise to play, and go to bed to work" (Ac II, sc I). In the proceeding parts of the play, lago reveals his conventional attitudes in a male-dominant society that pollutes Othello's thought as well, lago says:" In Venice they [women] do let Heaven see the pranks. They dare not show their husbands: their best conscience. Is not to leave undone, but keep unknown" (Act III, scn III). These lines allude to the same fact that lago is unfaithful to his wife and all Venetian women, because he believes they don't avoid the wrong-doing, instead they stoop to do the wrong, hence they try to keep them unknown. As it is seen the veins of male-dominated authority are apparent as lago talks in riddles, mocks and insults his wife and the women of Venice. His discourse is full of canivalistic disrespect and insulting of women, presumably more on Desdemona. lago is unable to show the real or pornographic image of the world he lives in, therefore his self recognition leads to his acceptance of his reductive definitions of sexuality and gender relations, hence his self consciousness validates his pornographic voice as a performer and personification of male sexual fantasies. Therefore, the family distortions of romantic convention, among the Venetians, reveal them to be equally versed in the values of the twentieth century and that of Bakhtin in his famous term, carnivalism. By conceiving Othello, lago tries to lead Othello's marriage to one of suspense and distortion, in order to make him aligned to the same trend, and consequently change the hierarchy toward a mail dominated world.

In the next quotation, there is a further aspect of Foucault's idea of his early work 'On Madness', which appears in Othello's vocations. Foucault believes that "individuals working within particular discursive practices can not think or speak without obeying the unspoken archive of rules and constraints; otherwise they risk being condemned to madness or silence" (45). Here, Othello is haunted by "unspoken archive of rules", as he asks himself "why he follows still the 
changes of the moon with suspicions?" In fact he asks himself that he should either obeys the archive of rules or be condemned to madness? Othello further says:

\author{
Why, why is this? \\ Think'st thou l'd make a life jealousy? To follow still the changes of the moon/ With fresh suspicions? No, to be once in \\ doubt,/ Is once to be resolved: exchange me for a goat, / When I shall turn the business of my soul/ To such exsufflicate \\ and blown surmises, / Matching thy inference, (Act III. Scn III).
}

This can further turn out to be used in a wider sense as in one occasion when Othello feels a pain upon his forehead, and Desdemona offers to bind it, he says: "your handkerchief is too little", this draws one's attention to an important fetishism implying that Desdemona bears no relation to Othello, since her handkerchief is little. This instance proves the fact that lago has succeeded to his goal which was the distortion of Othello's marriage, because Othello rejects Desdemona's handkerchief, and he believes it to be too little due to the same fact that he is overcomed by the dominant authority. This further approves that, Othello's identity is instable; it is reinforced by his interaction with other speaking subjects. Embroidering on that, Bakhtin says, "the instability of identity embodies the contradictory prescription of one's dialogue rather than operating as the fully valid voices" $(1973,45)$. This can somehow be linked to the point of view of cultural diagnosis.

There is no relation between Desdemona as the occident, and Othello as the orient. This is a fact not limited to the imaginative geography; in turn it is constructed on cultural distinction between the occident and the orient, inflecting them with racial differences, and long-term ideology about the Orient as the other, and it is all due to the authority of power and geographical centrality of occident. This is buttressed by a cultural discourse relegating and confining the non-occidental to a secondary radical cultural and ontological status even when Desdemona says "I think the sun where he [Othello] was born drew all such humor from him" (Act III, Scn IV), this can transparently reveal the anti - orientalistic tendency of Desdemona. Similarly, the stolen handkerchief by Emilia and its aftermath consequences are heavily overloaded with substances of colonialism. In fact, it is the stealing of culture by the dominated discourse. In the next section, Orientalism becomes more apparent in what Othello says about the robbed handkerchief:

Tis true. There's magic in the web of it. A sibyl that had numbered in the world. The sun to course two hundred compasses In her prophetic fury sewed the work. The worms were hallowed that did breed the silk, And it was dyed in mummy which the skillful conserved of maiden's hearts (Act III, scn IV).

In these lines, Othello draws our attention to the new knowledge of Orientalism. These lines imply that, we have on one hand an isolated cultural sphere, believed to be freely and unconditionally available to weightless theoretical speculation and investigation, and, on the other, a debased political sphere, where the real struggle is supposed to occur between the interests. Even when Cassio gives the misplaced handkerchief to Bianca, it highlights another point of Orientalism, and colonization that contains cultural experience or the fact that every cultural form is quintessentially hybrid, which is followed by another mimic culture, like Bianca who is to mimic the sewing design of handkerchief, which is another form of colonization in art. In Bakhtin's words, "It is presented not in a private, egotistic form, severed from the other spheres of life, but as something universal, representing all the people. It is contained not in the biological individual, not in the bourgeois ego, but in the people, a people who are continually growing and renewed" $(1968,27)$. Similarly, the separation of the orient and occident is laid bare in Desdemona's death bed, when Othello says, "It is the cause, it is the cause, my soul" (Act V, scn II), and prior to this bloody scene, when Desdemona says:

Tis meet I should be used so, very meet. How have I been behaved that he might stick. The small'st opinion on my least misuse? (Act IV, Scn II).

In the former quotation, Othello intends to kill Desdemona, and the phrase, "it is the cause" means you [Desdemona] are the pivotal cause of our combination or the hybrid of the orient as me and the occident as yourself and I [Othello] is to divide them in to two apparently separate spheres. Even Desdemona is cautious of the fact that is apparent after her marriage in the latter conversation especially in the phrase "on my least misuse". Desdemona's least misuse is her separation of occidental origin to wed an oriental Othello, hence she is victimized, and this marriage is consequently doomed and destined to crash. 


\section{Conclousion}

Despite the fact that Shakespeare's tragedies were written centuries before, they usually confer with the social conditions of humanity out of time and place. Therefore, it is visible that Shakespeare's Othello offers some hidden repository of Bakhtin's ideas. As you see, Shakespeare's Othello abound with the different voices which show the case of polyphonism ,it is also foregrounded by some of Focalutian ideas. The same background produces the different approaches including power-craving, feminism, colonialism, polyphonism and carnivalism. All of these approaches prescribe by the difference which is introduced by a dominated, hidden power. At first, the same difference produces by the difference of cultures as a second culture. After it, there will be some persistence among subjects against the same power which differentiates the various cultures and calling them as the inferior. The same resistance causes the clash of struggles which is then replaced with different trends like colonialism, polyphonism and Carnival. . . etc. Such trends are the sources of author's empathy and sympathy with both the people who live in his arena and those who will live in the future, because the message of humanity is immortal.

\section{References}

Bakhtin, Mikhail.(1981). The Dialogic Imagination: Four Essays, ed. Michael Holquist, trans. C. Emerson and M. Holquist. University of Texas Press, Austin.

. (1973).Problems of Dostoevsky's Poetics, trans. R.W. Rotsel, Ardis, Ann Arbor.

(1968). Robelais and His world, Trans. Helene Iswolsky Cambridge, MA: MITP.

Bressler, Charles E. Literary Criticism: An Introduction to Theory and

Practice. Prentice Hall. New Jersey, 2007.

Bristol, Michael. (1985). Carnival and Theater: Plebeian Culture and the Structure of Authority in Renaissance England. Methuen. London.

Foucault, Michel. (1977). Language, Counter-Memory, Practice, selected Essays and Interviews, ed. D.F. Bouchard. Basil Blackwell. Oxford; Cornell University press, Ithaca.

Mishra, P.(2011). "A Deconstructive Stylistic Reading of Keats' Ode on a Grecian Urn". 3L: The Southeast Asian Journal of English Language Studies, Vol 17(2): $49-58$.

Medvedev, P.N. and Bakhtin, Mikhail. (1978). The Formal Method in Literary Scholarship: A Critical Introduction to Sociological Poetics, trans. A.J. Wehrlel. Johns Hopkins University press. Baltimore and London.

Nietzche, F. (1968). The will to power Ed. Walter Kaufmann. Trans. Walter Kaufmann, and R.J.Hollingdale. New York. Vintage.

Selden, Raman. (2007). Practicing Theory and Reading Literature: An Introduction. Billing and Sons Ltd. Worcester.

Woolf, Virginia. (1929). A Room of One's Own, Hogorth Press, London. 